\title{
Investigation of Stone Columns' Role in Reinforcing Coastal Embankments Using Plaxis
}

\author{
Ahadiyan. J. ${ }^{1}$, Esmaeilzadeh .F.F. ${ }^{2}$, R.Aghamajidi ${ }^{3}$ \\ ${ }^{1}$ Associated Professor of Hydraulic Structures, Shahid Chamran University (SCU), Ahwaz, Iran. \\ (Ja_ahadiyan@yahoo.com) \\ ${ }^{2}$ Master Expert of GIS in Shahid chamran university, Ahvaz, Iran \\ (Feridani0220@gmail.com) \\ ${ }^{3}$ Professor assistant, Islamic azad university (iau), Sepidan branch. \\ roozbeh1381@yahoo.com
}

\begin{abstract}
The issue of optimizing reinforcing factors in stabilization of the stone slopes has constantly been of interest to geo-technique and geo-mechanic researchers due to great expenses of such operations, and instability and slides of these slopes owing to lack of enough reinforcement. In this study, are investigated the numerical and schematic role of stone in reinforcement of coastal embankments. Thereby, sample reinforced and non-reinforced embankments are modeled, and their function is compared under the same loading, thus settlements are an indicator of instability. The comparison of two embankments proves that critical displacement in reinforced embankments occurs less and in a larger distance from surface. In general, stone columns reduce function of displacement through dispersing stress and expansion of failure wedge. The results revealed that reinforcement of embankment reduces vertical displacement (39\%) and horizontal displacement (56\%).
\end{abstract}

Keywords: Slope Stability, Reinforcement, Stone Column, Plaxis

\section{Introduction}

Any natural or artificial slope of the ground made of stone, earth or a combination of both is called embankment. Instability and slide of natural and artificial slopes is a common phenomenon in Iran and other countries i. e. (Taheri and Behbahani, 2006). Displacement and slide of the ground including earth and stone have significant harmful effects on roads, tunnels, water and sewage lines, buildings, etc i. e. (Chen and Liu, 1990). These slides and instabilities result in damage and block of arterial roads or reduction of their function. Thereby, financial burden of control, maintaining, repairing, and rebuilding is placed on authorities. These instabilities may lead to casualties. In fact, natural failure of slopes due to the weight of the mass or earthquakes, long and heavy rains, or floods may endanger people using roads down the slopes. Often limit equilibrium, characteristic lines, and limit analysis methods are used to analyze slopes. Limit analysis is one of the most powerful solutions in soil mechanics which includes upper bound and lower bound methods. In this method the position of answer toward exact answer is determined. Giger and Krizek (1975 \& 1976) and Michalowski (1989) are among researchers investigated slope stabilities using upper bound limit analysis for 3D slope stability problems. Askari (2010) developed and modified Michalowski's method and improved his answers. To eliminate the limitation, it is required to use rotational failure mechanism. Thereby, we developed the algorithm suggested by DeBuhan and Garnier (1998) and created a rotational failure mechanism. Sarvghadi (2010) investigated stone and earth stability and different methods of increasing the stability of stone and earth slopes. Also, Ariafar and Abrishami (2010) in a study, modeling geo-grid effect on dynamic behavior of reinforced soil using Plaxis, investigated geogrid effect. Tabarsaz and Soroush (Summer 2010), have done a research, numerical analysis of reinforced earth by stone group. Sharifipour, et al (2009) have done a study, laboratory investigation of bearing capacity and settlements of clay beds strengthened by stone columns in reinforced and non-reinforced modes. Charbel at al (2011) evaluated the unsaturated soil geotextile interface behavior. That research showed some results of a laboratory study on the mechanical behavior of unsaturated soil-geotextile interfaces using a specially modified direct shear apparatus. The results of these researchers indicated that the peak shear strength of the soil-geotextile interface increases nonlinearly with the soil suction. In addition, while inconclusive, the effect of suction on the post-peak shear strength of the interface was negligible in some cases. Shiau and Merfield (2011) investigated the effects of embankment geometry on confidence coefficient of undrained stability of footing slopes. Dazhong and Yungming (2012) presented their paper on nonlinear failure stress of un-drained clay slopes using finite element method. Also, Melnikova and Shirshov (2011) studied simulated levee stability against different floods as a part of flood control project. Choudhary, et al (2009) reported the results of different tests of shear strength of foot of slopes reinforced by geo-grid on a laboratory model and compared the results with the results of non-reinforced slopes. Also, they showed the positive effect of reinforcement of slope by geo-grid and increase of distance between slope and slope foot. Abusharar and Han 
(2012) employed 2D analysis to estimate safety factor of embankments reinforced by stone columns over undrained clay soil. This study investigates the effects of friction angle at stone materials, clay cohesion, and friction angle of embankment, embankment height, and water table on confidence coefficient and reinforcement of coastal embankments by problematic clay soil. The materials used for levees of meanders are according to materials of bed and margin of these rivers. Griffiths et al (2011) studied the stability of slopes with Probabilistic infinite scheme. In their methods the research activity in the mechanics of landslides has led to renewed in the infinite slope equations. On the other hand this scheme need for a more general framework for giving insight into the probability of failure of long slopes involving non-homogeneous vertical soil profiles and variable groundwater conditions. Wang and Mark (2012) studied the breached levee system at the 17th Street Canal has been independently by conducting total and effective stress analyses. Their results mentioned in contrast to the total stress analyses by the interagency performance evaluation task force and the independent levee investigation team, and also the effective stress analysis have been presented in their paper with the soil pore water interaction, and have been demonstrated evidences of initiation and mobilization of the localized shear strain. Timothy et al (2014) analyzed the soil compressibility in transient unsaturated seepage. They showed the transient seepage analyses using a floodwall case study that as soil compressibility of the under seepage layer decreases. In addition the transient results also indicated that uplift factors of safety during the flood event are about $22 \%$ higher than those at steady state. The effect of soil compressibility can delay or accelerate the onset of uplift water pressure increase from the initial steady-state conditions. On the above literature review, in this research were used the stone column for stabilization of costal embankments. To achieve this purpose, demonstrate settlement using Plaxis Model with consolidation analysis.

\section{Materials and Methods}

According to above material, this research is based on modeling the role of stone columns in stability of coastal slopes. Thereby, in all modeling the load of $50(\mathrm{KPa})$ with its center in the middle of upper surface of slope is used. The level of underground water is at +4 to zero elevation in base of foundation (representation in a bottom at Fig.1). Mohr-Coulomb model is used to model soil behavior, and consolidation analysis is employed for settlements calculations. When it is required to consider time to analyze distribution elimination of additional water pure pressure saturated clay, consolidation analysis is selected. Typically, consolidation analysis without additional loading is done after un-drained elastic analysis. Also, it is possible that loads are applied during consolidation analysis. Thereby, the period of applying load is 24 hours (i.e. calculation continues for 24 hours). The Geometric characteristics of embankment are shown in Fig. 1.

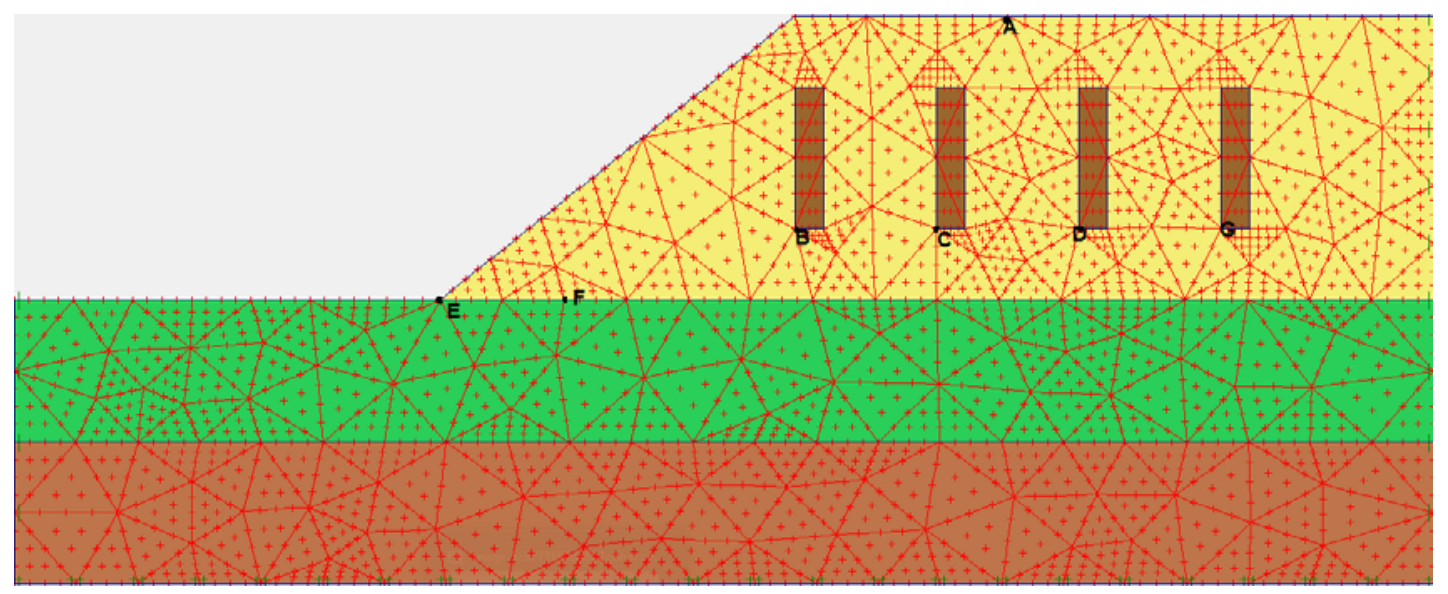

Fig 1.Geometry of embankment meshed by columns

On modeling columns, while they have same as geometrically and geo-technically the section of columns is square $(40 \mathrm{~cm} \times 40 \mathrm{~cm})$. The columns are $2 \mathrm{~m}$ height and their transverse distance is $2 \mathrm{~m}$ (edge to edge). The column is built of rubbles (average diameter of $8 \mathrm{~cm}$ ). The specifications of materials of columns are shown in table 1.

Table 1. Specifications of embankment

\begin{tabular}{|c|c||c||c|c|c|c|c|c||c||c|}
\hline \hline Color of soil & $\psi$ & $\phi$ & $\begin{array}{c}\mathrm{C} \\
\mathrm{KPa})\end{array}$ & $v$ & $\begin{array}{c}\mathrm{E} \\
(\mathrm{KPa})\end{array}$ & $\mathrm{Kx}$ & $\mathrm{Ky}$ & $\gamma_{\text {sat }}$ & $\gamma_{n}$ & Type of soil \\
\hline \hline Brown & 0 & 35 & 0.1 & 0.3 & 20000 & 1 & 1 & 20 & 18 & Sand \\
\hline Green & 0 & 30 & 10 & 0.35 & 1200 & 0.01 & 0.01 & 18 & 17 & Sand and clay \\
\hline Yellow & 0 & 24 & 20 & 0.35 & 2000 & 0.001 & 0.001 & 17 & 15.5 & Clay \\
\hline
\end{tabular}




\section{Results and Discussion}

Settlements are due to reduction of volume of soil lower layers and increased stresses. Settlements includes immediate and long-term (consolidation) subsidence. Immediate subsidence is fast. Long-term subsidence of aggregates caused by a change in volume, due to removing the water of soil, is fast; but long-term settlements of fine aggregates is slow (consolidation subsidence may last for several months or several years). For cohesive soil, pre-consolidation pressure plays an important role in rate of settlements. Also, secondary subsidence of cohesive soil is caused by soil creep due to fixed effective stress. Thus, aggregates are affected by immediate subsidence whereas cohesive soil is affected by consolidation and secondary settlements.

As shown in Fig. 2, despite the extension of displacement area due to absorb of stress by lateral columns, overall displacement has reduced significantly. On the surface of embankment, changes are observed in the area of bearing load (i.e. area of bearing maximum stress). The red area shows that in absence of columns this amount of displacement would start from surface and enters critical and red phase at foundation. Non-reinforced areas experience much more displacement in critical phase compared to reinforced areas.

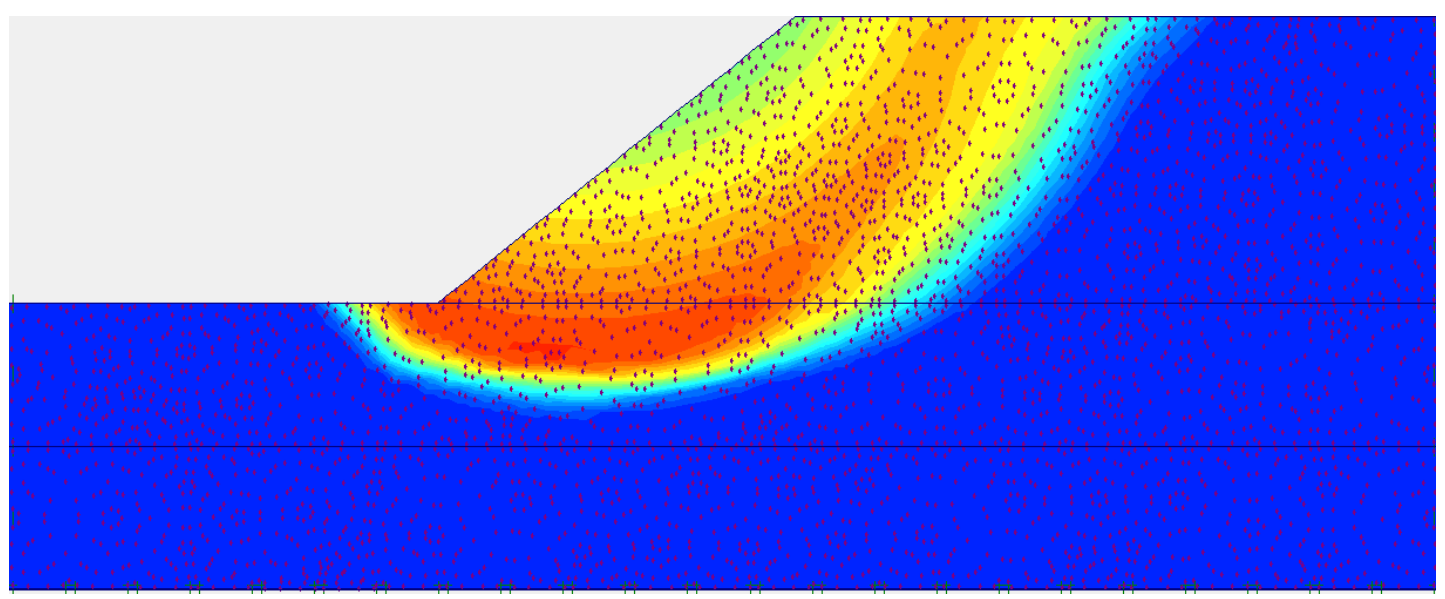

Fig 2. Overall displacement of embankment in absence of columns

In general, stress is distributed by columns. Although columns expand failure wedge (area of displacement), the stress of elements and displacement is reduced. In fact, areas displaced by shared load are increased, but rate of displacement is reduced.

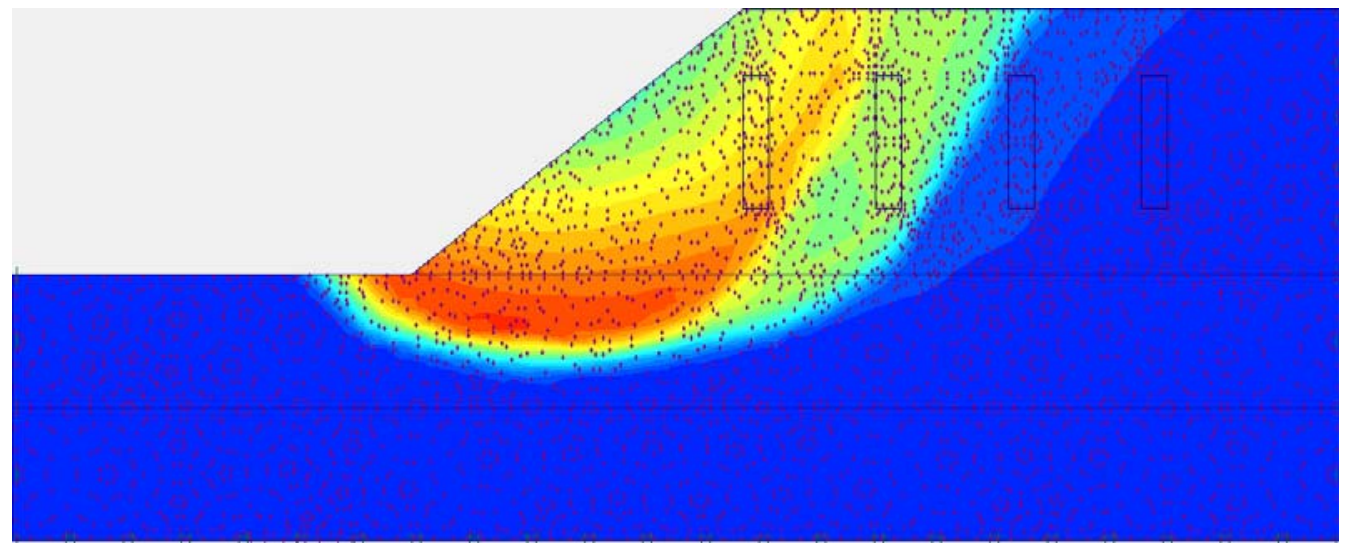

Fig 3. Overall displacement of embankment in presence of columns

Fig. 4 and Fig. 5 show vertical displacement of elements. Comparison of vertical, overall, and horizontal displacements (Fig. 6 and Fig. 7) shows that elements of embankment mostly move horizontally. This is the same for reinforced and non-reinforced embankments. 


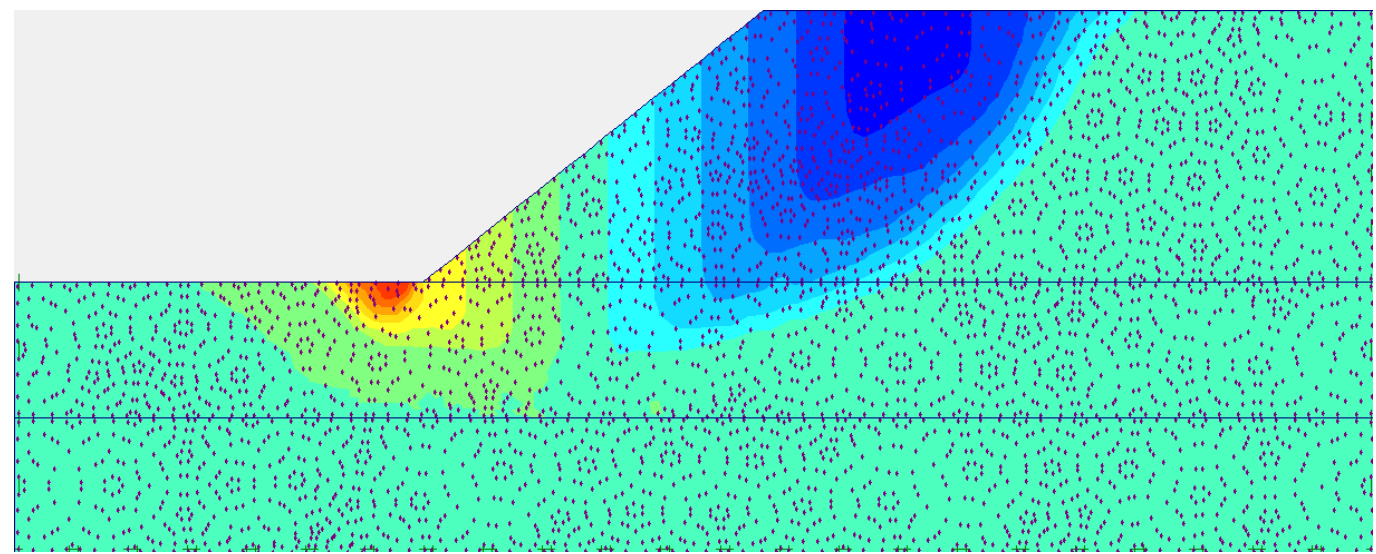

Fig 4.Vertical displacement of elements of non-reinforced embankments

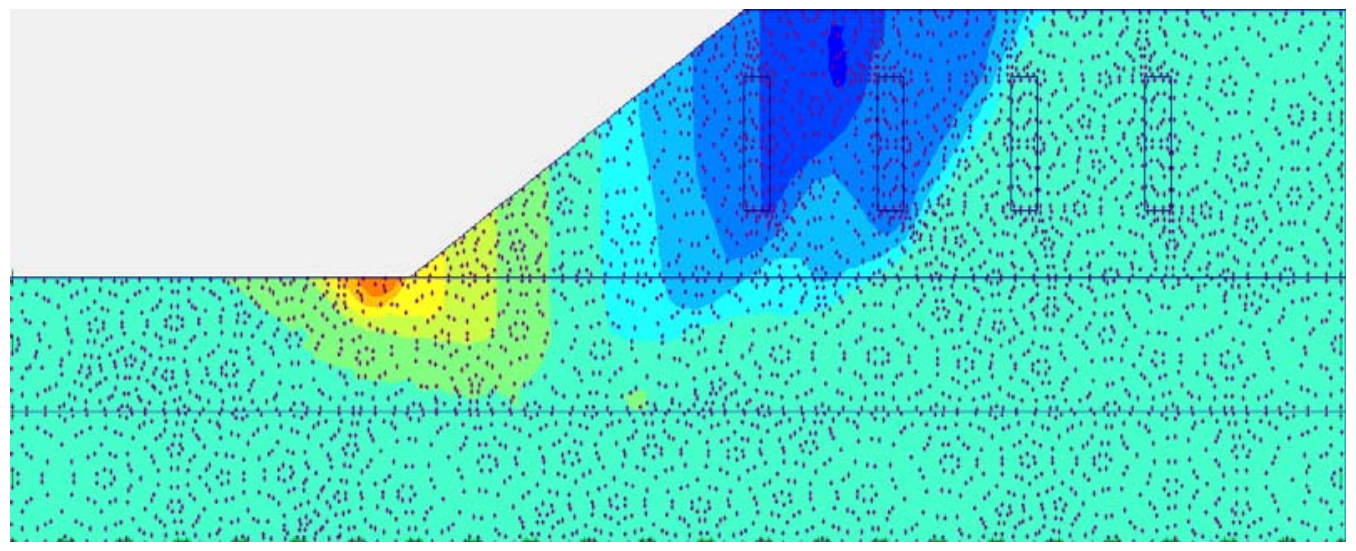

Fig 5. Vertical displacement of elements of reinforced embankments

Columns reduce subsidence significantly. As shown in figures, after reinforcing embankments, the surface of subsidence is increased, but its amount is lower and controlled. Displacements of slopes are seen as protrusions. Columns reduce protrusion of foot slope Fig 6 and 7, vertical displacement of embankment elements, display proper function of columns. The columns do not prevent critical displacements, but reduce them significantly. Similar to previous figures, horizontal displacement is increased, but movement of critical elements is reduced specifically. According to the function of elements, columns absorb stress and expand their area of action. Thereby, stress in critical elements is reduced (Figure 8). In other words, the columns have distributed stresses to more elements and reduce too much stress in some elements caused by loading and weight of soil. Although the above results are obtained from schematic figures, increased safety and stability of slopes are due to increased shear strength of soil by columns.

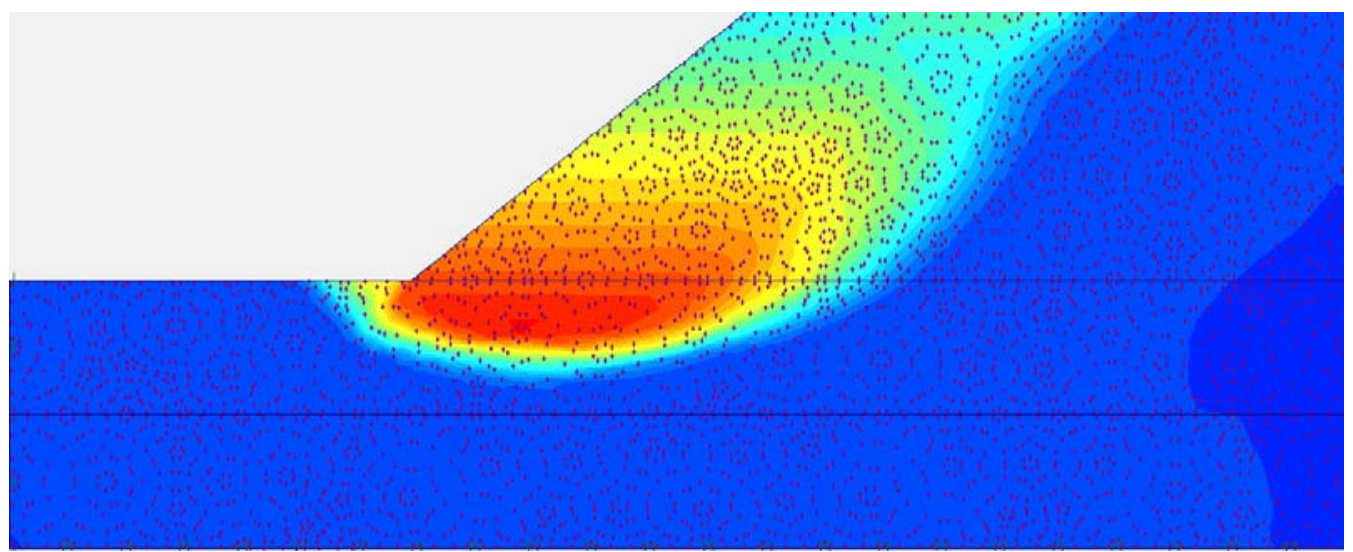

Fig 6. Horizontal displacement of non-reinforced embankment 


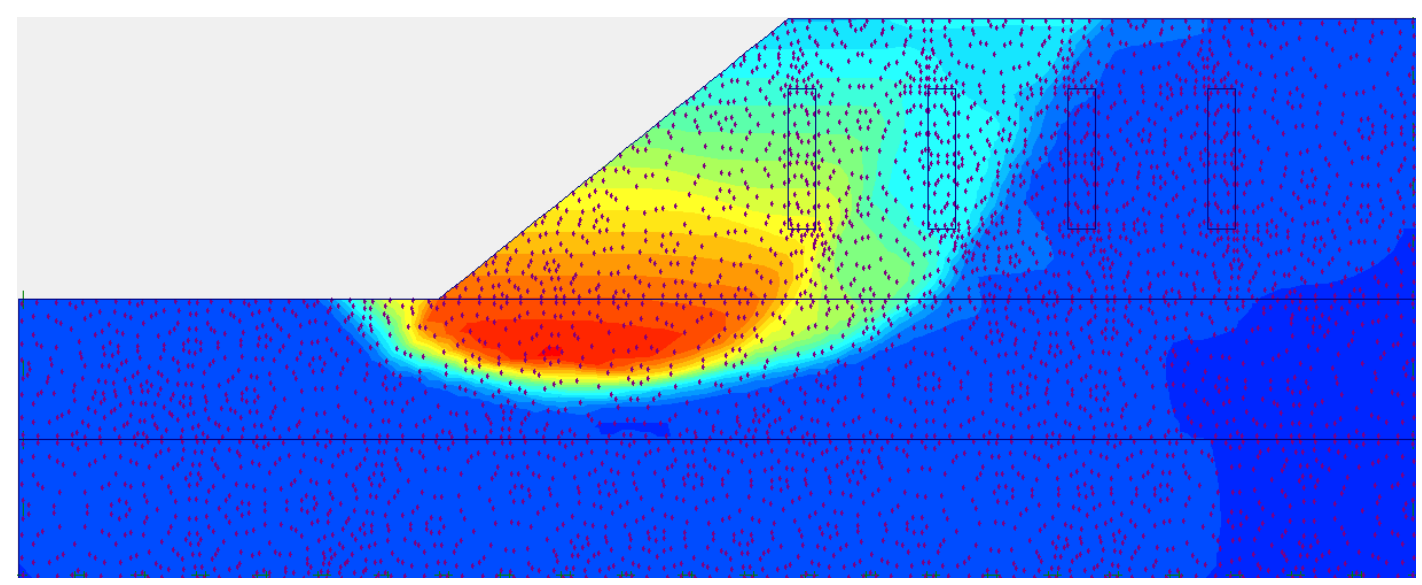

Fig7. Horizontal displacement of reinforced embankment

Table 2. Vertical displacement of elements

\begin{tabular}{|c|c|c|c|c|c|c|c||}
\hline G & F & E & D & C & B & A & Points \\
\hline \hline 0 & 280 & 325 & -179 & -247 & -250 & -451 & $\begin{array}{c}\text { Vertical displacement of } \\
\text { non-reinforced embankment(mm) }\end{array}$ \\
\hline 0 & 224 & 269 & -110 & -222 & -228 & -332 & $\begin{array}{c}\text { Vertical displacement of reinforced } \\
\text { embankment(mm) }\end{array}$ \\
\hline
\end{tabular}

Table 3. Horizontal displacement of elements

\begin{tabular}{|c||c|c|c|c|c|c|c||}
\hline G & F & E & D & C & B & A & Points \\
\hline 0 & 689 & 456 & 50 & 240 & 320 & 20 & $\begin{array}{c}\text { Horizontal displacement } \\
\text { of non-reinforced embankment(mm) }\end{array}$ \\
\hline 0 & 495 & 340 & 22 & 110 & 150 & 20 & $\begin{array}{c}\text { Horizontal displacement } \\
\text { of non-reinforced embankment(mm) }\end{array}$ \\
\hline
\end{tabular}

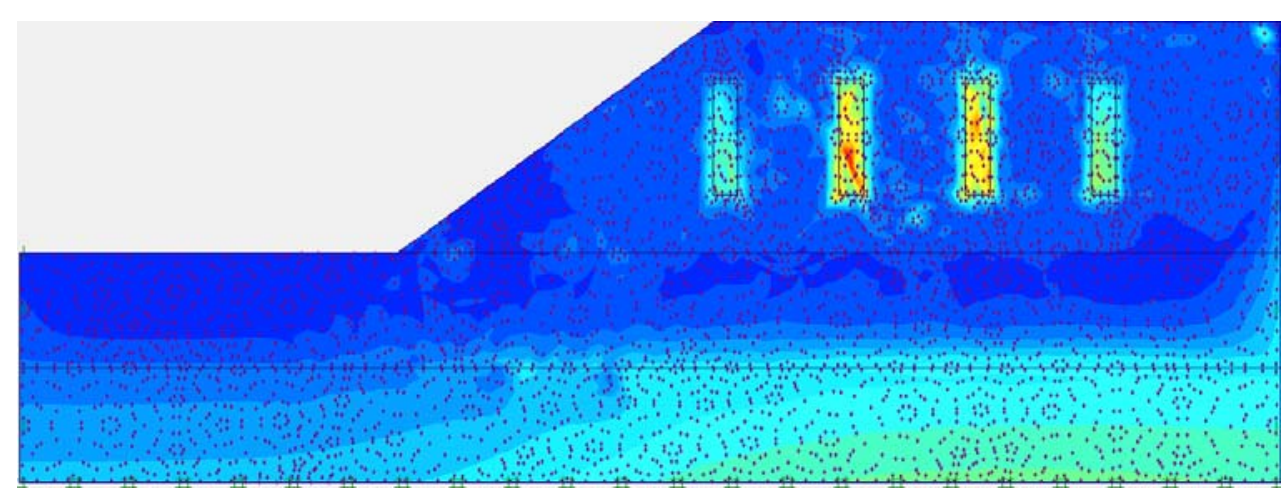

Fig 8. Effective stress in embankment

Table 4. Reduction of displacement rate

\begin{tabular}{|c|c|c|c|c|c|c|c||}
\hline G & F & E & D & C & B & A & Points \\
\hline \hline 0 & 20 & 18 & 39 & 11 & 9 & 27 & Reduction of vertical displacement (\%) \\
\hline 0 & 29 & 26 & 56 & 54 & 53 & 0 & Reduction of horizontal displacement (\%) \\
\hline
\end{tabular}

According to table 4, reinforcement of embankments plays an important role in decrease of horizontal displacements. Point (A) on the surface of embankment does not experience significant horizontal displacement and reinforcement does not change the rate of displacement, since at this point stress is vertical. Reinforcing embankments may decrease vertical and horizontal displacement by 39\% and 56\%, respectively. 


\section{Conclusions}

By moving towards failure wedge, the displacement of reinforced and non-reinforced embankments is increased (Fig.2 and Fig.3). The critical displacement of reinforced embankment is lower and slower compared with nonreinforced embankment. Critical and red phase of displacement of reinforced embankment starts from foundation. More elements of reinforced embankment are displaced but their rate of displacement is decreased. In fact, columns disperse stress, and more elements bear stress and loading. Stone columns disperse stress to decrease critical and overall displacement. Critical vertical displacement of non-reinforced embankment moves towards foundation, but in reinforced embankment, it moves towards column surface. Due to much more hardness of columns, they absorb more stress compared to other parts of structure. Reinforcement has more effects on decrease of horizontal displacement. Reinforcing embankment decreases vertical and horizontal displacements by $39 \%$ and 56\%, respectively. Reinforcing embankment does not influence horizontal displacement of points only experiencing vertical stress.

\section{References}

[1] Abusharar, S.W. and Han, J. 2011. Two-dimensional deep-seated slope stability analysis of embankments over stone columnimproved soft clay. Journal of Engineering Geology, Elsevier Publications, 120(4): 103-110.

[2] Ariafar, M. and Abrishami, S. 2010. Effect of geo-grid reinforced soil modeling on dynamic behavior using Plaxis. The Fifth National Congress on Civil Engineering (in Persian), PP 1-8.

[3] Askari, F. 2010. Three-Dimensional analysis of homogeneous and non-homogeneous slopes in static and dynamic mode using upper bound theorem of limit analysis, Ph.D. Dissertation Thesis (In Persian), Department of civil engineering, The university of Tehran, Iran.

[4] Charbel, N., Khoury, G. A. and Miller, K. H. 2011. Unsaturated soil-geotextile interface behavior. Journal of Geotextiles and Geomembranes, 29(1): 17-28.

[5] Chen, W.F. and Liu, X. L. 1990. Limit Analysis in Soil Mechanics. Elsevier Science Publishing Company Inc., New York.

[6] Choudhary, A. K., Jha, J. N. and Gill, K. S. 2009. Laboratory investigation of bearing capacity behavior of strip footing on reinforced fly-ash slope. Journal of Geotextiles and Geomembranes, Elsevier Publications, 28(4): 393-402.

[7] Dazhong, Li and Cheng, Y. 2012. Lower bound limits analysis using nonlinear failure criteria. International Conference on Structural Computation and Geotechnical Mechanics, Elsevier Sciences, Vol. 5, PP. 170-174.

[8] DeBuhan, P. and Garnier, D. 1998. Three dimensional bearing capacity analysis of a foundation near a slope. Soil and Foundations, Tokyo, 38(3): 153-163.

[9] Griffiths D. V., J. Huang, and Fenton, G. A. 2011. Probabilistic infinite slope analysis. Journal of Computers and Geo-techniques, Elsevier Publications, 38(4): 577-584.

[10] Giger, M. W. and Krizek, R. J. 1975. Stability analysis of vertical cut with variable corner angle." Journal of Soils and Foundation, Tokyo, 15(2): 63-71.

[11] Giger, M. W. and Krizek, R.J. 1976. Stability analysis of vertical corner cut with concentrated surcharge load. Journal of the Geotechnical engineering, ASCE, 102(1): 31-40.

[12] Melnikova, N. B, Shirshov, G. S. and Krzhizhanovskaya, V. V. 2011. Virtual Dike: multi-scale simulation of dike stability. International Conference on Computational Science, Elsevier publications, Vol. 4, PP. 791-800.

[13] Michalowski, R. L. 1989. Three dimensional analyses of locally loaded slopes. Geo-technique Journal, London, 39(1): 27-38.

[14] Sarvghadi, M. 2010. Stabilize soil and rock slopes. Monthly Special-Research Engineering, Architecture and Urbanism, period 11, No. 52. (In Persian).

[15] Shiau, J. S. and Merfield, R. S. 2011. Un-drained stability of footing slopes. International Journal of Geo-mechanics, 11(5): 381-390.

[16] Taheri, M. and Behbahani, B. M. 2006. Floods for Urban Planning and Architecture Research Center of Iran (in Persian), Vol. 1, PP. 20-28, 1st Printing. Tehran.

[17] Timothy, D. S., Navid, H. J., Aaron, L. L. and Thomas, L. 2014. Soil compressibility in transient unsaturated seepage analyses. Canadian Geotechnical Journal, 2014, 51(8): 858-868.

[18] Wang, X. and Mark, C. 2012. Failure analysis of the breached levee at the 17th Street Canal in New Orleans during Hurricane Katrina. Canadian Geotechnical Journal, 2012, 49(7): 812-834. 